\title{
Primary gastric melanoma: a rare presentation
}

\author{
Manoj P Rai, ${ }^{1}$ Divyesh Reddy Nemakayala, ${ }^{1}$ Samanjit Kaur Kandola, ${ }^{1}$ Mukta Sharma ${ }^{2}$
}

\begin{abstract}
${ }^{1}$ Department of Internal Medicine, Michigan State University/Sparrow Hospital, Lansing, Michigan, USA ${ }^{2}$ Department of Internal Medicine, Michigan State University, Lansing, Michigan, USA
\end{abstract}

\section{Correspondence to Dr Manoj P Rai, manoj.rai@hc.msu.edu}

Accepted 10 May 2018

\section{DESCRIPTION}

A man in his early 50s presented to the emergency department with complaints of abdominal pain and dark tarry stools. He reported 3/10 burning left upper quadrant abdominal pain that started 2 days before. The pain radiated to the epigastric region and the patient was unsure what exacerbates or relieves the pain. Starting around the same time, the patient had 8 to 10 black tarry stools daily, which were loose in consistency, which were coming out of his ostomy bag. Review of systems was positive for weakness, fatigue, nausea, abdominal pain and change in stools. The patient has a history of T4 caecal adenocarcinoma with metastasis to bladder diagnosed in 2014, for which he underwent right hemicolectomy, low anterior resection, radical cystectomy and colostomy with urostomy that was reversed 2 years later. He also underwent chemotherapy/radiation therapy with (FIFLORI) leucovorin calcium (folinic acid), fluorouracil and irinotecan hydrochloride. Vitals showed a temperature of $97.5^{\circ} \mathrm{F}$, pulse 87 beats per minute, respiratory rate 16 breaths per minute and blood pressure 119/69 mm Hg. On physical examination, abdomen was soft, mildly distended, tender to palpation in the left upper quadrant and the left epigastric region, and no rebound or guarding was present. The colostomy was filled with black stool. Skin examination and ophthalmology examination were unremarkable. Urostomy had adequate output with no blood noted. Laboratory work-up was remarkable for acute normocytic anaemia with haemoglobin of $6.2 \mathrm{~g} / \mathrm{dL}$. The patient received continuous intravenous normal saline infusion and $1 \mathrm{U}$ of packed red blood cell transfusion. Haemoglobin improved to $7.0 \mathrm{~g} / \mathrm{dL}$. General surgery team performed emergent oesophagogastroduodenoscopy, which showed a large ulcerated mass extending from the greater

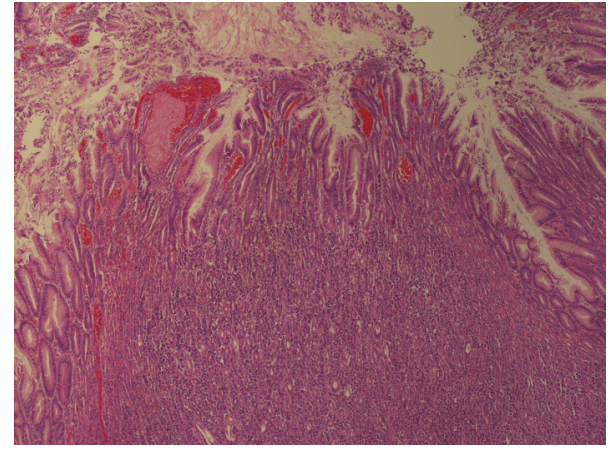

Figure 2 H\&E staining at low power $(\times 4)$ showing gastric mucosal surface.

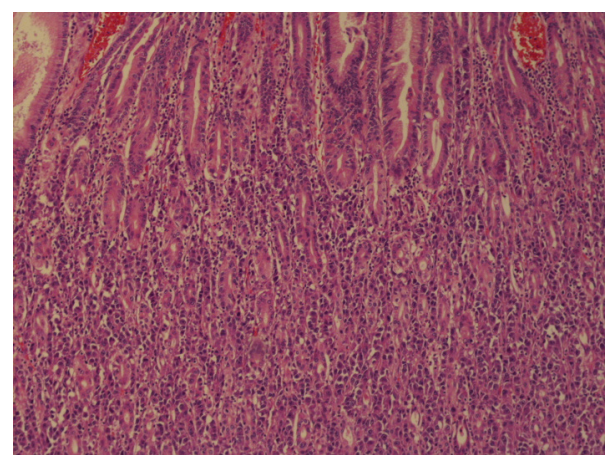

Figure 3 H\&E staining at medium power.

curvature that was actively bleeding (figure 1 ). A partial gastrectomy was performed, and a J tube was placed about $20 \mathrm{~cm}$ away from the ligament of Treitz. It was a large ulcerated mass within the stomach; histopathology showed (figures 2, 3 and 4) extensive involvement of the adjacent mucosa within the lamina propria that extended virtually
A Check for updates

To cite: Rai MP,

Nemakayala DR, Kandola SK, et al. BMJ Case Rep Published Online First: [please include Day Month Year]. doi:10.1136/bcr-2018224914

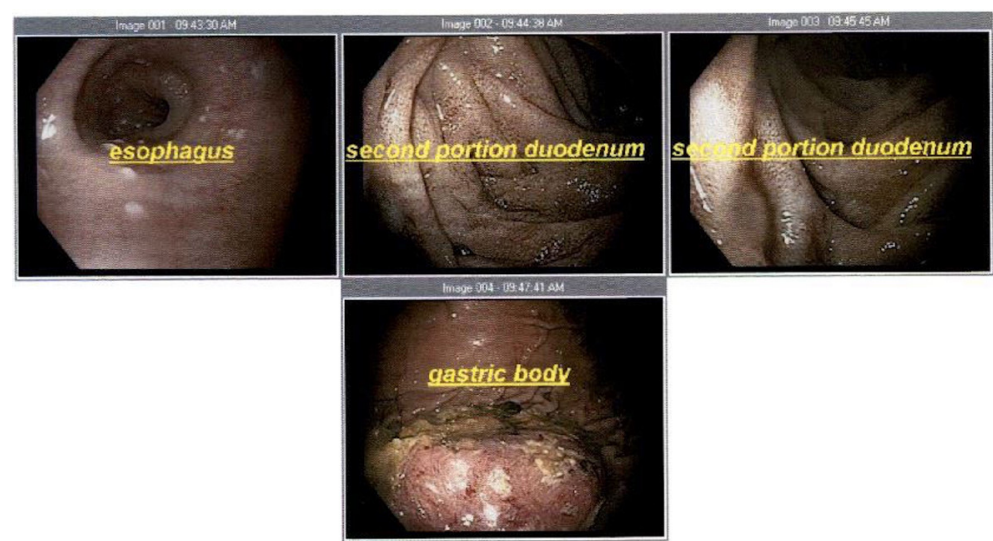

Figure 1 Oesophagogastroduodenoscopy showing a large ulcerated mass extending from the greater curvature with active bleed. 


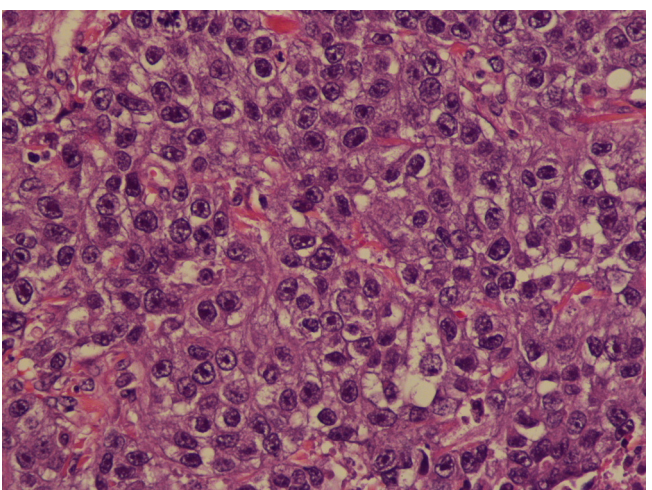

Figure $4 \quad H \& E$ staining at high power.

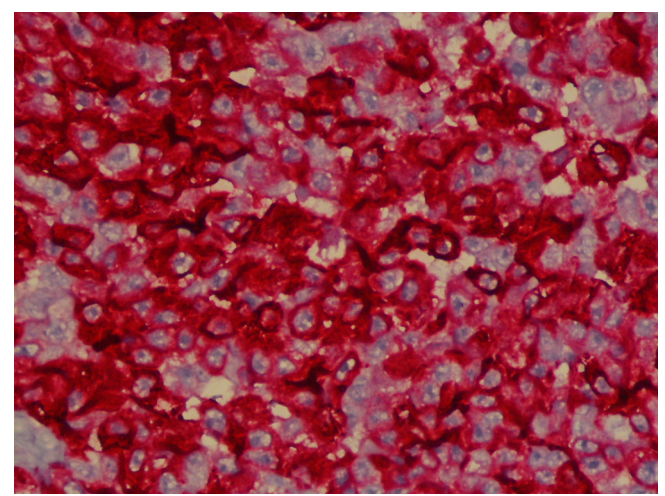

Figure 5 Immunostaining positive for SOX-10.

to the serosal surface. There was widespread capillary lymphatic space involvement. The atypical cells were growing in solid sheets and appeared discohesive; cells were large with a high nuclear to cytoplasmic ratio and prominent large nucleoli. There were no identifiable glands. There was widespread mitotic activity and necrosis. There was no identifiable pigment formation, and there were areas of vascular invasion. Immunohistochemical stains showed strong staining with vimentin, melan A and SOX-10 (figure 5). The atypical cells of interest did not demonstrate staining with cytokeratin 7 , cytokeratin

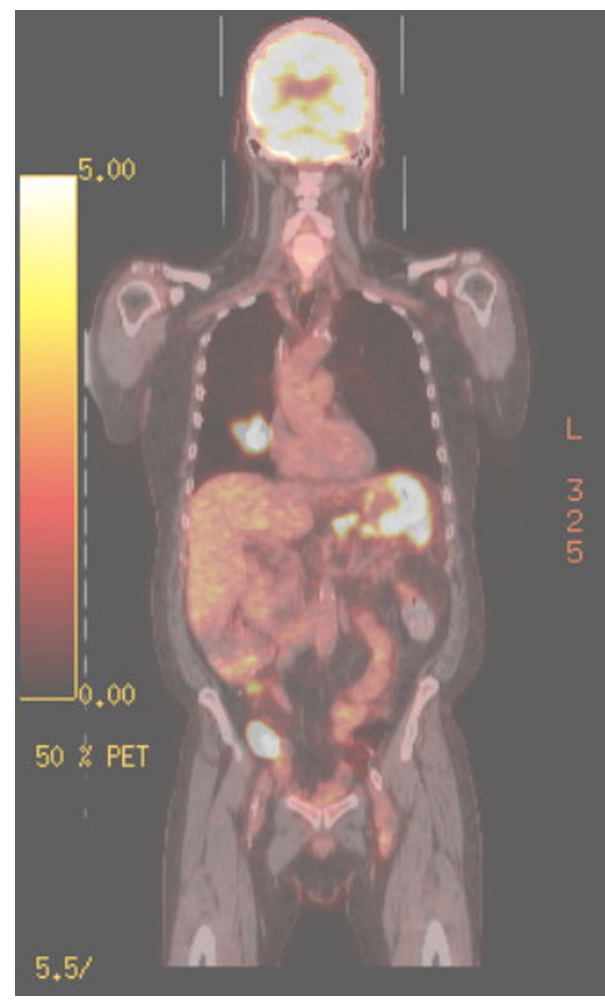

Figure 7 PET/CT (coronal section) showing FDG-avid lymphadenopathy in the gastrohepatic ligament up to $1.1 \times 1.4 \mathrm{~cm}$ with intense uptake SUV 10.5 .

20, pan-keratin or CAM5.2. Molecular study was positive for p.V600E B-Raf proto-oncogene (BRAF) mutation. The above findings were suggestive of melanoma. PET/CT showed fludeoxyglucose-avid lymphadenopathy in the gastrohepatic ligament up to $1.1 \times 1.4 \mathrm{~cm}$ with intense uptake standardised uptake value (SUV) 10.5 (figures 6 and 7). There was also interval enlargement of dominant lobular right middle lobe mass approximating $5.3 \mathrm{~cm}$ AP, SUV 15.1, biopsy of which showed an abscess with no malignant cells. Malignant melanoma is commonly known to manifest in the skin. Primary melanoma of the gastrointestinal

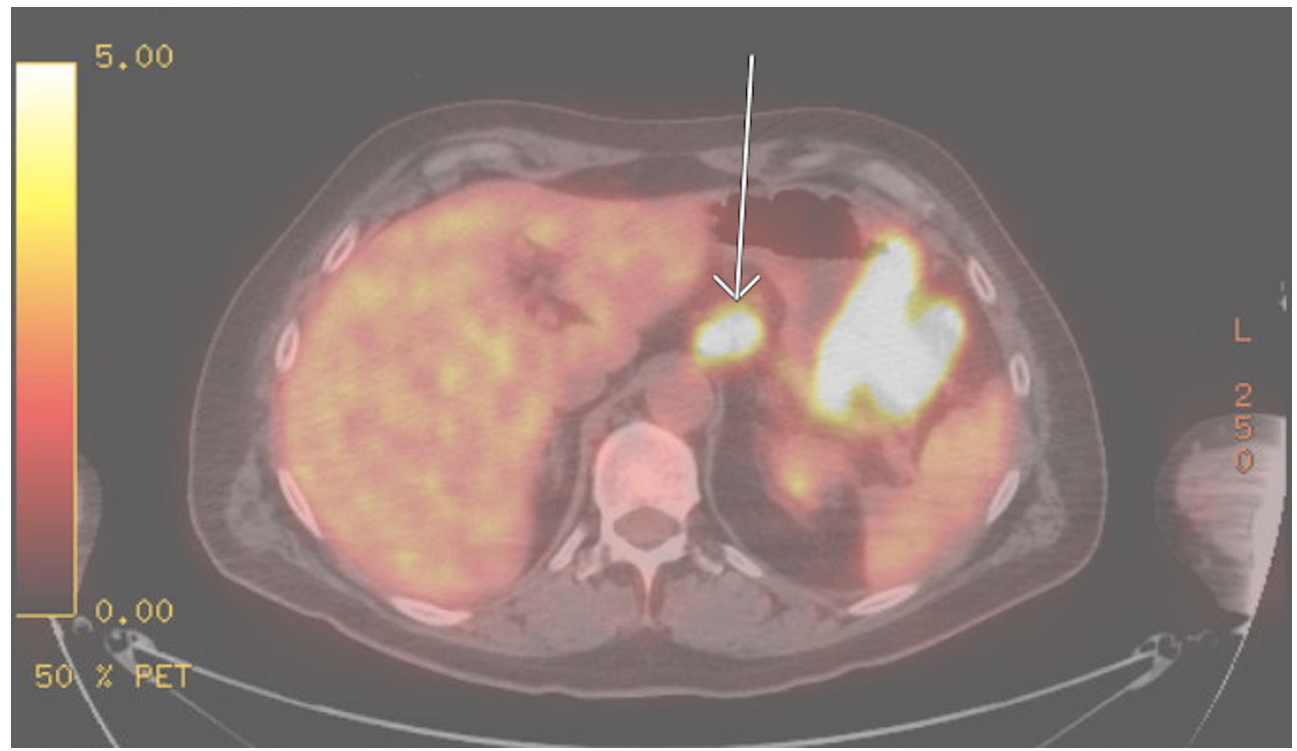

Figure 6 PET/CT (axial section) showing FDG-avid lymphadenopathy in the gastrohepatic ligament up to $1.1 \times 1.4 \mathrm{~cm}$ with intense uptake SUV 10.5 . 


\section{Learning points}

- Primary gastric melanoma is an extremely uncommon presentation of melanoma.

- Amelanotic melanoma such as the one in this case can be missed in poorly differentiated tumours unless appropriate staining tests are performed.

- Primary malignant melanoma of the stomach may be an underdiagnosed phenomenon.

- Early detection and surgical intervention is critical for longterm cure, though overall prognosis is very poor.

tract is extremely uncommon, and it has been reported to arise from the mucosa of the oesophagus, anorectum and small bowel. To date, fewer than 15 cases of primary gastric melanoma have been reported in the literature. ${ }^{1}$ It can present with weight loss, upper gastrointestinal bleeding and anaemia. Positive immunohistochemical stains for S100 protein, Melan-A and HMB-45 antibodies are highly sensitive. Primary gastric melanoma is diagnosed when there are no concurrent lesions, the absence of a history of melanoma or prior removal of atypical melanocytic lesions from the skin or other organs. Prognosis is extremely poor due to the lag in diagnosis, aggressive nature of the tumour and easier metastasis due to the rich lymphatic and vascular supply of the gastrointestinal mucosa. ${ }^{2}$

Contributors MPR, DRN and SKK wrote the manuscript. MS revised the manuscript.

Funding The authors have not declared a specific grant for this research from any funding agency in the public, commercial or not-for-profit sectors.

Competing interests None declared.

Patient consent Not required.

Provenance and peer review Not commissioned; externally peer reviewed.

(c) BMJ Publishing Group Ltd (unless otherwise stated in the text of the article) 2018. All rights reserved. No commercial use is permitted unless otherwise expressly granted.

\section{REFERENCES}

1 Ravi A. Primary gastric melanoma: a rare cause of upper gastrointestinal bleeding. Gastroenterol Hepatol 2008;4:795-7.

2 Sachs DL, Lowe L, Chang AE, et al. Do primary small intestinal melanomas exist? Report of a case. J Am Acad Dermatol 1999;41:1042-4.

Copyright 2018 BMJ Publishing Group. All rights reserved. For permission to reuse any of this content visit

http://group.bmj.com/group/rights-licensing/permissions.

BMJ Case Report Fellows may re-use this article for personal use and teaching without any further permission.

Become a Fellow of BMJ Case Reports today and you can:

- Submit as many cases as you like

- Enjoy fast sympathetic peer review and rapid publication of accepted articles

- Access all the published articles

Re-use any of the published material for personal use and teaching without further permission

For information on Institutional Fellowships contact consortiasales@bmjgroup.com

Visit casereports.bmj.com for more articles like this and to become a Fellow 